\title{
Influence of Moringa oleifera derivates in blends of PBAT/PLA with LDPE
}

\author{
Cristiane Medina Finzi-Quintão ${ }^{1 *}$, Kátia Monteiro Novack,2, Ana Cláudia Bernardes-Silva ${ }^{1,3}$, \\ Thais Dhayane Silva², Lucas Emiliano Souza Moreira² and Luiza Eduarda Moraes Braga²
}

\begin{abstract}
${ }^{1}$ Programa de Pós-graduação em Engenharia de Materiais, Rede Temática em Engenharia de Materiais REDEMAT, Escola de Minas, Universidade Federal de Ouro Preto - UFOP, Ouro Preto, MG, Brasil ${ }^{2}$ Departamento de Química, Universidade Federal de Ouro Preto - UFOP, Campus Morro do Cruzeiro, Ouro Preto, MG, Brasil

${ }^{3}$ Departamento de Química, Biotecnologia e Engenharia de Bioprocessos, Universidade Federal de São João del-Rei - UFSJ, Campus Alto Paraopeba, Ouro Branco, MG, Brasil
\end{abstract}

*finzi@ufsj.edu.br

\begin{abstract}
There are few studies about Moringa oleifera derivates in polymer developments where vegetable oil was used as a plasticizer and a biodegrading agent. The polymerization of moringa oil (MO) was carried out assisted by microwaves without catalysts presence. There aren't studies about the polymerization of MO using microwaves technology. Moringa's oil and its polymer (PMO) were used as a biodegrading agent for mixtures of low density polyethylene (LDPE) with poly(butylene adipate-co-terephthalate)/poly(lactic acid) (PBAT/PLA). The mixtures producted films that were characterized and submitted to biodegradation analysis in order to discuss the influence of moringa components. Results showed that both moringa components improved thermal properties and reduced the crystalline phase of the mixture. The addition of PMO had improved the biodegradation capacity up to five times while MO had improved it up to three times. The results showed the greatest influence of moringa components on biodegradation of mixtures with cited polymers.
\end{abstract}

Keywords: biodegradation, biopolymers, microwaves, Moringa oleifera.

\section{Introduction}

Conventional polymers such as low density polyethylene (LDPE), high density polyethylene (HDPE), polypropylene (PP) and others are classified as bioinert materials. They have a long life time and can represent an environmental problem due to their difficult discard. The use of biodegradable polymers represent a way to reduce the amount of plastic waste disposed in landfill[ ${ }^{[1]}$.

In USA, the biodegradable bags certified by the U.S Composting Council are being used in San Francisco for transportation of compostable materials. In Brazil, the biodegradable bags are being used without certification and blended with high density polyethylene. The mixture of biodegradable polymers and conventional polymers produce a plastic with low degradability behavior. This plastic needs the presence of additives to improve mechanical properties lost due to the mixture.

The biopolymers as (poly( $\varepsilon$-caprolactone) (PCL), polyhidroxybutirate (PBH), poly(lactic acid) (PLA) and poly(butylene - adipate - co - terephthalate) (PBAT) are hetero-chain polymer. They can be used as a substitute for conventional polymers in production of plastic bags, medicinal products, food packages and others. The backbones of hetero-chain polymers have atoms such as oxygen and nitrogen and these atoms make the polymer susceptible to hydrolysis and biodegradation process ${ }^{[2]}$.

PLA is a biopolymer that has been attracting attention due to its stiffness, biodegradation and biocompatibility ${ }^{[3,4]}$. PBAT is an aliphatic aromatic copolyester, biodegradable, hydrophobic, flexible, it presents a better processability than other biopolymers and similar mechanical properties to polyethylene ${ }^{[5]}$. The purpose of the mixture of PBAT and PLA was to obtain a cheaper polymer, with better mechanical properties than PLA and with high biodegradation behavior.

The biodegradation can occur by two simultaneous processes: enzymatic degradation and water induced hydrolysis. Some plastics (e.g PLA) will not biodegrade without prior hydrolysis ${ }^{[2]}$. The highest rate of hydrolysis means a better and faster biodegradation due to the better microbe's attack to the carbon backbone.

Some polymer mixtures are immiscible and need to be compatibilized aiming the optimization of the interfacial tension and the increase of the adhesion between the phases when in solid state ${ }^{[6]}$. In mixtures of LDPE with PLA, the use of compatibilizers reduces the material cost and improves the toughness, increasing the deformability and reducing the tensile strength in comparison with PLA ${ }^{[3,6]}$ Plasticizers exchange the intermolecular bonds among polymer chains and improve the conformational changes, that can result in an increase in the deformability. The plasticized polymers present a reduction on their glass transition and processing 
temperature, which enables the melt processing ${ }^{[7]}$. Plasticizers can also reduce the stiffness of polymers, increase the elongation and tear strength and change thermal characteristics reducing the processing temperature ${ }^{[7]}$.

Vegetable oils (VOs) such as castor, buriti, palm and M. oleifera oils were blended with some conventional polymers to improve the processability of them ${ }^{[8-14]}$. They are composed by triglycerides (esters of glycerol) with three long chain fatty acids that vary depending on the source of the oil. The most common fatty acids are oleic acid (C18:1), linoleic acid (C18:2) and linolenic acid (C18:3) but the number of double bonds varies for different oils ${ }^{[15-18]}$.

According to literature, several routes can synthesize VOs based polyols ${ }^{[8,11]}$, but the most used one is the epoxidation of the double bonds followed by the reaction of the epoxy groups with ring opening reagents. Epoxidized VOs are used as plasticizers for polymers as LDPE, PP, PS and PVC ${ }^{[17,19]}$, due to the presence of olefinic chains on fatty acids ${ }^{[7]}$. Meanwhile, there are few studies that investigated if the vegetable oil, in natura, presents characteristics of plasticizer or compatibilizer, aiming to improve the biodegradation properties and to enhance the mechanical properties of polymers.

The Moringa oleifera oil was extracted from seeds of a small tree native to northern India called Moringa oleifera Lam which belongs to the Moringaceae family. MO presents a high nutritional importance due to the presence of important nutrients and antinutrients: minerals, vitamins, tannins, fibers and fatty acids ${ }^{[20,21]}$. The seed of M. oleifera is composed by $38 \%$ in mass of fatty acids like oleic acid $(63.4 \%)$, linoleic acid (3.1\%), palmitic acid (8.4\%) and stearic acid $(8 \%)^{[18,22,23]}$. Oleic acid fatty has high stability due to its low unsaturation and this fact favors the polymerization process ${ }^{[24]}$.

Henri Dou et al. verified the researches and developments about M. oleifera Lam and showed that there are 356 patents, 267 references on Medline and 552 references on Web science between 2010 and 2015. They are about nutrition, water treatment, moringa leaf extract and medicine effects ${ }^{[22,25,26]}$.

In this study, the polymer of moringa oil (PMO) was obtained using microwaves irradiation without catalyzers presence. The use of microwave (MW) technology in the organic synthesis is widely described in literature ${ }^{[17,26-29]}$ due to its advantages, such as safety, speed, effectiveness and rate enhancement by selective heating. Polymerization under microwaves irradiation is becoming common for synthesis of polyesters, biodegradable polymers and open ring ${ }^{[27,30]}$. According to literature, the kinetics of reactions using microwaves is better than the conventional heating ${ }^{[17,23,31]}$.

The Brazilian plastic bags are produced by mixtures of $50 \%$ of biodegradable polymer (PBAT/PLA) with $50 \%$ of high-density polyethylene (HDPE). The biodegradable polymer used to produce market bags is compostable and its discarded in landfills, dumping ground or in environmental impair the expect biodegradation behavior. The aim of this study was to investigate the behavior of M. oleifera oil (MO) and its polymer (PMO) obtained by MW, in mixtures of disposal plastics as LPDE (named PE) with PBAT/PLA (named PB), improving the biodegradation behavior without a loss in the mechanical properties.
In literature, the mass proportion of vegetable oil used in mixtures of polymers as additive for commodities is up to $3 \%$ due to the loss of mechanical properties. In this manuscript, the mass concentration of the vegetable oil or the mass concentration of its polymer is up to $15 \%$ in order to restore the mechanical properties lost with the mixture of disposal polymers. The results for MO showed that it decreased the crystallinity of the mixture of PE with PB (named PEPB) and improved the thermal stability and the biodegradation. The tests of respirometry showed significant improvement in the biodegradation capacity of PEPB, in comparison to previous studies for the film without oil. Meanwhile, the use of PMO showed the increase of $80 \%$ of biodegradation capacity comparing to the mixture PEPB and $35 \%$ in comparison to similar mixture of MO with PEPB. Thermal properties are similar for both moringa components but the microscopy and biodegradation tests showed that MO presents a plasticizer behavior and PMO is a compatibilizer between commercial plastics.

\section{Materials and Methods}

\subsection{Moringa oleifera compounds}

Moringa oleifera oil was extracted by seeds during 8 hours in Soxhlet extractor.

Moringa oleifera polymer was obtained by polymerization of moringa oil assisted by microwaves irradiation. The polymerization was carried out in a microwave domestic oven with $0.85 \mathrm{~kW}$ of potency. $50 \mathrm{~mL}$ of $\mathrm{MO}$ were polymerized in a becker of $100 \mathrm{~mL}$ during 1 hour every day up to 16 days.

\subsection{Films preparing}

LDPE was obtained from food bags and the PBAT/PLA from market bags. The samples were produced by the mixture of MO or PMO with cited polymers in specific proportions up to $10 \mathrm{~g}$ in presence of $100 \mathrm{~mL}$ of xylene. The system was heated up to $110^{\circ} \mathrm{C}$ with manual stirring during $1 \mathrm{~min}$ every 10 minutes. After 120 minutes, the heating was stopped and the mixture was stirred until the extra solvent was dried. Those mixtures were dried at room temperature for 36 hours or until complete solvent evaporation. Dried blends were pressed in a hot press machine at 2.5 ton, during 5 minutes and $150{ }^{\circ} \mathrm{C}$.

The controller film was composed by $2.5 \mathrm{~g}$ of PE with $2.5 \mathrm{~g}$ of PB. The highest presence of moringa components was investigated during the preparation of the samples. In this work 10 samples ar used to explain MO and PMO influence in mixtures of PE with PLA/PBAT. The mixture of $50 \mathrm{wt} \%$ of PE with $50 \mathrm{wt} \%$ of PB was named PEPB. The mixtures of $\mathrm{MO}$ with $\mathrm{PE}$ and $\mathrm{PB}$ produced the samples: M5-45-50, M10-40-50, M15-35-50, M20-40-40, M30-30-40. The mixtures of PMO with $\mathrm{PE}$ and $\mathrm{PB}$ produced the samples: P5-45-50, P10-40-50, P15-35-50, P20-40-40, P30-30-40.

\subsection{Characterization}

Thermal Gravimetric Analysis (TGA) was carried out in a TA Instruments, SDT 2960 Simultaneous DTA-TGA model, at $20{ }^{\circ} \mathrm{C} / \mathrm{min}$, in inert $\left(\mathrm{N}_{2}\right)$ atmosphere, interval: $0-700{ }^{\circ} \mathrm{C}$. 
Gel Permeation Chromatography (GPC) was carried out in a Shimadzu LC-20AD Model, solvent: THF, column: 1 Waters linear e 1 Shimadzu GPC 803, flow: 1.0 mL. $\mathrm{min}^{-1}$, injection: $20 \mu \mathrm{L}$, conc.: $0.2 \%(\mathrm{p} / \mathrm{v})$.

Fourier Transform Infrared Spectroscopy (FTIR) analysis was carried out in a FT-IR System Spectrum GX/Perkin Elmer.

Scanning Electron Microscope (SEM): was carried out in an Scanning Electron Microscopy Vega 3 TESCAN, HV: $25.0 \mathrm{kV}$, det: SE, SEM MAG: $100 \mathrm{x}-4 \mathrm{kx}$.

Wide Angle X-Ray Diffraction (WAXD) was carried out in an EDX-720/800HS Energy Dispersive X-Ray Fluorescence Spectrometer. WXRD diffractograms were obtained with $\mathrm{Cu}$ radiation $(\mathrm{k}=1,541 \mathrm{a})$ at $40 \mathrm{kV}$ and $20 \mathrm{~mA}$. The analysis was made at $20^{\circ} \mathrm{C}$ and at angles between $5-60^{\circ}$, with a step of $0.025^{\circ}$ and rate of $1 \% \mathrm{~min}$. The relative crystallinity was determined by the equation $\mathrm{Xc}=\mathrm{Ap} / \mathrm{Ap}+\mathrm{Ab}$, where $\mathrm{Xc}$ is the relative crystallinity, Ap is the crystallinity of WXRD and $\mathrm{Ab}$ is the amorphous area.

Tensile strength test (TST) was carried out in an EMIC DL-2000, Trd18, cross-head speed: $500 \mathrm{~mm} / \mathrm{min}$, load: 200 kgf. ASTM - D1708-13.

The biodegradation analyses were carried out according to NBR14283-199, which specifies the procedures to use Bartha Respirometer (Figure 1). According to NBR, 0.6g of sample was buried in $50 \mathrm{~g}$ of compostable soil (Figure 1F), under controlled temperature $\left(28^{\circ} \mathrm{C}\right)$, free $\mathrm{CO}_{2}$ ambient,

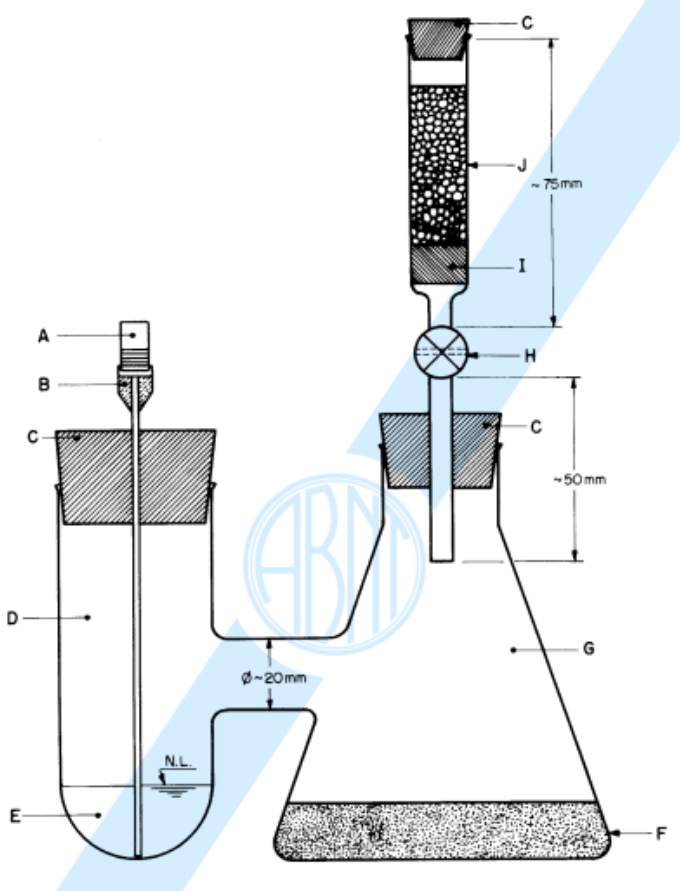

Figure 1. Bartha Respirometer. (A - cannula cap; B - Cannula ( $\varnothing \mathrm{i}$ between $1 \mathrm{~mm}$ and $2 \mathrm{~mm}$ ) with cannon Luer; C - Rubber Stopper; D - Side arm $(\varnothing 40 \mathrm{~mm} \sim \mathrm{H} \sim 100 \mathrm{~mm})$; E - KOH solution; F - Solo; G - Erlenmeyer flask (250 mL); H - Valve; I - support (glass or cotton wool); J - ascarita filter ( $\varnothing 15 \mathrm{~mm} \sim \mathrm{H} \sim 40 \mathrm{~mm}$ ) Font: NBR14283-199. during 9 weeks. $\mathrm{CO}_{2}$ production due to biodegradation was quantified every day with the titration of $\mathrm{KOH}$ (Figure 1E) converted in $\mathrm{K}_{2} \mathrm{CO}_{3}$

Soil and sample are conditioned in the vessel without addition of water (Figure 1F) or contact with operator. After 19 weeks, the weight and samples morphology were analyzed.

The experimental system was composed by one Bartha Resp. without sample, three Bartha Resp. with controller sample, and three Bartha Resp. with the study sample disposed in temperature controlled ambient $\left(28^{\circ} \mathrm{C}\right)$.

\section{Results and Discussions}

\subsection{GPC}

According to GPC analysis, MO has a molecular weight near to $1214 \mathrm{~g} \cdot \mathrm{mol}^{-1}$. After polymerization assisted by microwaves, GPC showed that PMO is composed of a mixture of components with $16 \%$ upper to 285,000 g. $\mathrm{mol}^{-1}$, $4 \%$ of molecular weight near to $1,229 \mathrm{~g} \cdot \mathrm{mol}^{-1}$ and $80 \%$ of high molecular weight near to 54,937 g.mol ${ }^{-1}$ what indicates the oil polymerization.

\subsection{FTIR}

Figure 2 exhibits the difference of IR spectra of $M$. oleifera oil and polymer. MO spectrum identified the absorption band at $3474 \mathrm{~cm}^{-1}$, which refers to hydroxyl groups formed by triglycerides hydrolysis. The thermal polymerization reduced the absorption band intensity due to the water loss. The absorption band at $3004-3009 \mathrm{~cm}^{-1}$ is typical of fatty acids as oleic acid and indicates the cis stretching of double bond $(=\mathrm{C}-\mathrm{H})^{[32-37]}$. This absorption band isn't present in PMO IV which confirms the breakage of the double bonds during polymerization process. The thermal polymerization was confirmed also by the loss of the double bond $(\mathrm{C}=\mathrm{C})$ identified at $1640 \mathrm{~cm}^{-1}$ of MO spectrum.

Mixtures with MO exhibit O-H group shifted from $3474 \mathrm{~cm}^{-1}$ to $3730 \mathrm{~cm}^{-1}$ caused by the triglycerides hydrolysis of oil. The absorption band at $1744 \mathrm{~cm}^{-1}$ that identifies the carbonyl of esters of PEPB. IR spectrum of MO samples exhibits the absorption band at $3004 \mathrm{~cm}^{-1}$ which confirm the presence of oleic acid, indicating the compatibility of the MO with PEPB.

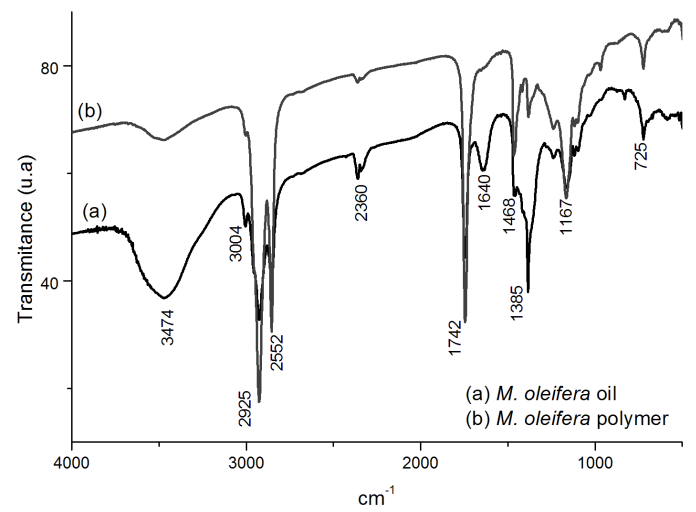

Figure 2. IR spectra of M. oleifera oil and M. oleifera polymer. 
IR spectrum of samples as P5-35-50 hasn't shown the presence of O-H group at $3720 \mathrm{~cm}^{-1}$ caused by the triglycerides hydrolysis of oil. The spectrum of P10-40-50 showed the shift of $\mathrm{C}=\mathrm{O}$ (PEPB) stretching of ester at $1744 \mathrm{~cm}^{-1}$ in to the carbonyl stretching of carboxylic acids at $1710 \mathrm{~cm}^{-1}$, indicating the influence of PMO in PEPB. The P15-35-50 spectra exhibit $\mathrm{O}-\mathrm{H}$ group at $3712 \mathrm{~cm}^{-1}$ even as the presence of oleic acid residue at $3009 \mathrm{~cm}^{-1}$. The absorption band between $1400-1300 \mathrm{~cm}^{-1}$ related to C-O of carboxyl acids disappeared and the spectrum showed bands at $1268 \mathrm{~cm}^{-1}$ and $1250 \mathrm{~cm}^{-1}$ related to $\mathrm{C}-\mathrm{O}$ of aromatic ethers of PBAT structure. PBAT absorption band appears at $1270 \mathrm{~cm}^{-1}$ and $1248 \mathrm{~cm}^{-1}$ by $\mathrm{C}-\mathrm{O}$ of aromatic ester groups. The $\mathrm{C}-\mathrm{O}$ of PLA appears at $1028 \mathrm{~cm}^{-1}$ of vinyl ether group. The $\mathrm{C}-\mathrm{H}$ wagging vibrations were found at $795 \mathrm{~cm}^{-1}$ for three adjacent hydrogens and $750 \mathrm{~cm}^{-1}$ for four adjacent hydrogens.

\subsection{Thermal analysis}

The Thermal Gravimetric analysis (TG) of samples and their original components showed that PEPB enhanced the thermal stability when MO was added into the mixtures chains (Figure 3).

M15-35-50 and M20-40-40 present a different stage of degradation and a higher thermal stability (Figure 3). As the M20-40-40 sample exuded during the hot press, M15-35-50 was used as a study sample. TG curves of M15-35-50 show two stages of degradation, the first stage occurring between $124{ }^{\circ} \mathrm{C}$ and $436{ }^{\circ} \mathrm{C}$ in which it lost approximately $63 \%$ of mass, and the second stage, with a loss of approximately $31 \%$. TG results confirms that there is a limit on the amount of oil to be added to the mixture of PEPB, which occurs during the hot press process. In fact, samples with MO concentration higher than 20\% also exuded during hot press and are considered unworkable.

TG curves of PMO samples showed a complex thermal degradation behavior which increased the thermal stability of PEPB (Figure 3). P5-40-50 and P15-35-50 samples exhibit higher thermal stability than P10-40-50, so P15-35-50 was used as a study sample.

Derivative Thermal Gravimetric analysis (DTG) of M15-35-50 determine the degradation temperature of mixture components. PLA degradation was identified at $351.5^{\circ} \mathrm{C}$, PBAT at $377.8^{\circ} \mathrm{C}$, MO at $391.2^{\circ} \mathrm{C}$ and LDPE at $483,8^{\circ} \mathrm{C}$. In fact, DTG curve of M15-35-50 indicates a compatibilizer behavior for moringa oil.

DTG curve of P15-35-50 showed higher thermal stability and complex thermal degradation behaviour (Figure 4). The temperature at $122.65{ }^{\circ} \mathrm{C}$ represents the water loss of $\mathrm{PB}$ and $\mathrm{PMO}$. The main degradation stage is divided in two temperatures, first at $393.7^{\circ} \mathrm{C}$ due to $\mathrm{PMO}$ and second at $399^{\circ} \mathrm{C}$ due to the interacting of PMO with the $\mathrm{PB}$ crystalline phase. The secondary degradation stage indicated relationship between the blend components. The interaction of PMO with the $\mathrm{PB}$ amorphous phase exhibit degradation temperature at
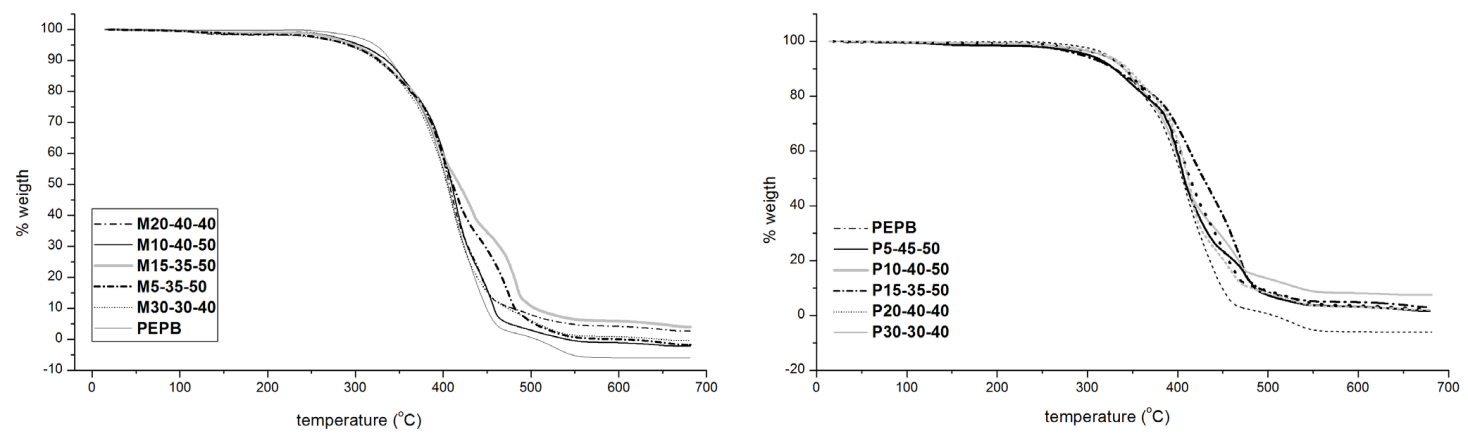

Figure 3. Comparative TG curves in inert atmosphere for samples with MO and PMO.
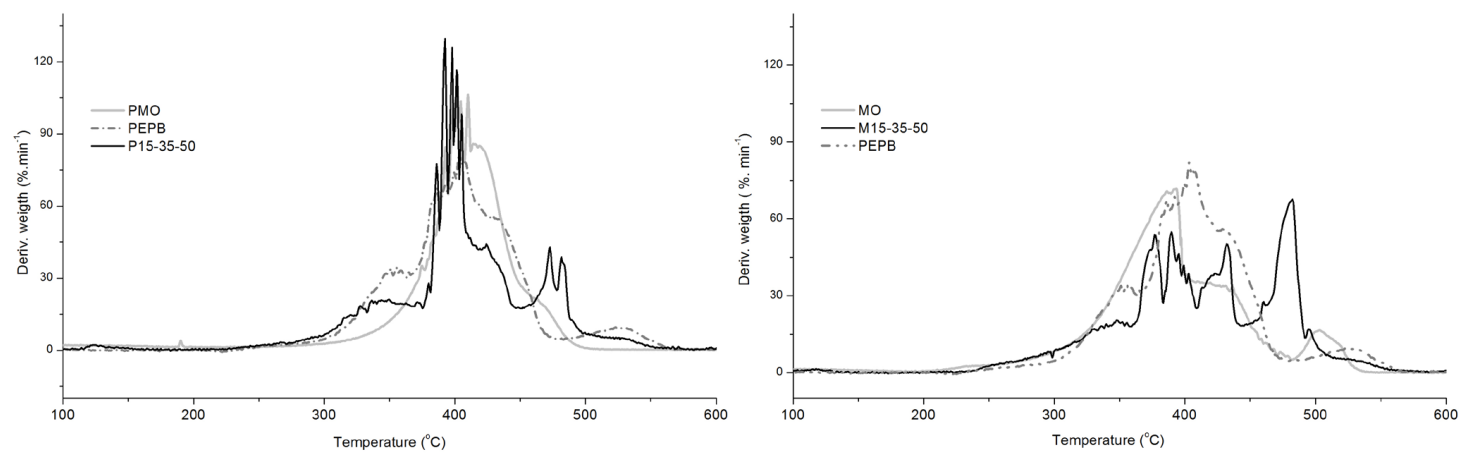

Figure 4. DTG comparative curves of M15-35-50, P15-35-50, MO, PMO and PEPB. 
$340{ }^{\circ} \mathrm{C}$ and for PMO interacting with $\mathrm{PE}$ the degradations temperatures were identified at $472{ }^{\circ} \mathrm{C}$ and $482{ }^{\circ} \mathrm{C}$.

Differential temperature curve (DTA) indicated two major stages for change of phase of mixtures. DTA curves for M15-35-50 and P115-35-50 showed the change of phase near to $126{ }^{\circ} \mathrm{C}$, which refers to polyethylene (Figure 5). $\mathrm{PB}$ phase was exhibited in MO15-35-50 by PBAT/PLA near to $396{ }^{\circ} \mathrm{C}$, PBAT at $436{ }^{\circ} \mathrm{C}, \mathrm{PBAT} / \mathrm{PE}$ at $484.6^{\circ} \mathrm{C}$ and $\mathrm{LDPE}$ at $499,6{ }^{\circ} \mathrm{C}$ (Figure 5). $\mathrm{P} 15-35-50$ exhibit $\mathrm{PB}$, at $406.9{ }^{\circ} \mathrm{C}$ referring to PBAT and $491.7^{\circ} \mathrm{C}$ referring to relationship of PBAT/LDPE (Figure 5). The PLA and PMO temperatures weren't explicit in DTA curve of P15-35-50, but the two defined stages indicate their interaction with PMO and PBAT, the plasticizer behavior of PMO.

\subsection{Wide X-ray diffractogram}

The x-ray diffractograms of MO and PMO exhibit similar amorphous behavior (Figure 6). The PMO hasn't presented any organization that indicates the increase or loss of crystallinity after thermal polymerization.

Diffractogram of PEPB (Figure 7) identified a semi crystalline material with characteristic peaks of LDPE and relative crystallinity of $55 \%$. Peaks at $20.6^{\circ}$ and $23.2^{\circ}$ are typical in crystalline phase of PBAT, the peak $29.6^{\circ}$ is related to PBT (butylene terephthalate) crystals and the peak $16.7^{\circ}$ is related to the crystalline phase of PLA. LDPE presents characteristic peaks identified at $2 \Theta=21.5^{\circ}$ and other at $2 \Theta=23.75^{\circ}$ (Figure 8) ${ }^{[38,39]}$.

Diffractograms of M5-45-50 and PEPB exhibit peaks close to $21.8^{\circ}$ and PEPB lost up to $4 \%$ of its crystallinity. The increasing of oil in mixture PEPB changed the main peak for $19.6^{\circ}$, close to MO characteristic peak and it exhibits a peak in $17.9^{\circ}$, close to the peak of the crystalline phase of PLA, which returns the relative crystallinity of $55 \%$ for PEPB. In M15-35-50, the relative crystallinity was reduced to $47 \%$ but the characteristic peaks of LPED in $21.68^{\circ}$ and $24.03^{\circ}$ were better defined than in the others samples.

The addition of PMO in mixture PEPB increased the base of the main peak at $21^{\circ}$ besides duplicated it (Figure 8). The intensity of second peak reduces from P5-45-50 to P15-35-50 while the base was increased. The diffractogram indicated that the amorphous phase of PMO interacted with the crystalline phase of PE from PEPB, reducing the crystallinity and increasing the processability.

\subsection{Mechanical tests}

Table 1 shows that mixture PEPB reduces the elongation and elastic modulus of LDPE and PBAT/PLA. from $450 \%$ of LDPE to $15 \%$ of PEPB. PB tensile stress was reduced from $43 \mathrm{MPA}$ to $8.9 \mathrm{MPA}$ and elastic modulus reduced
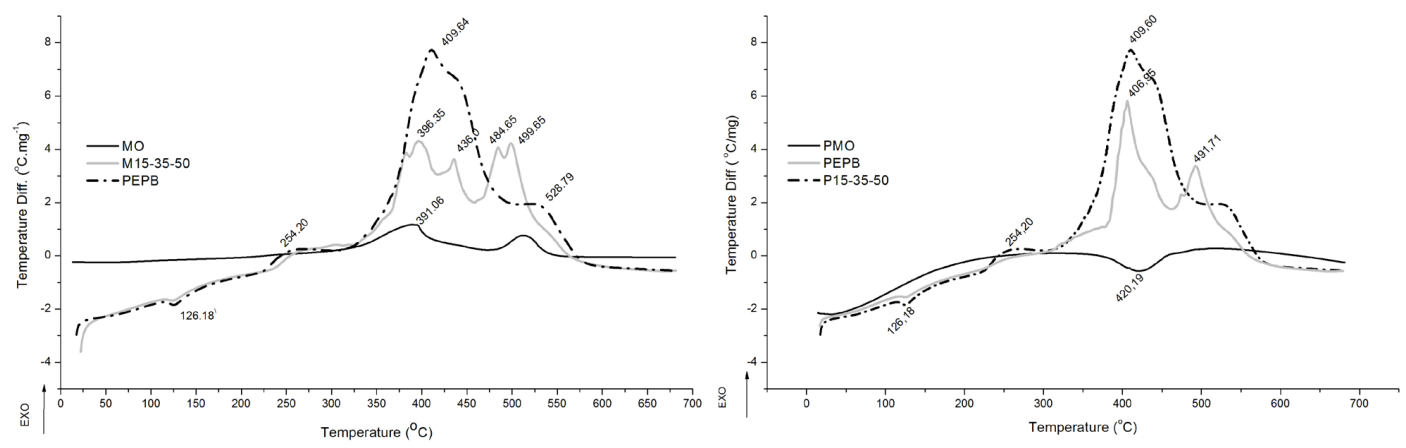

Figure 5. DTA comparative curves of M15-35-50, P15-35-50, MO, PMO and PEPB.
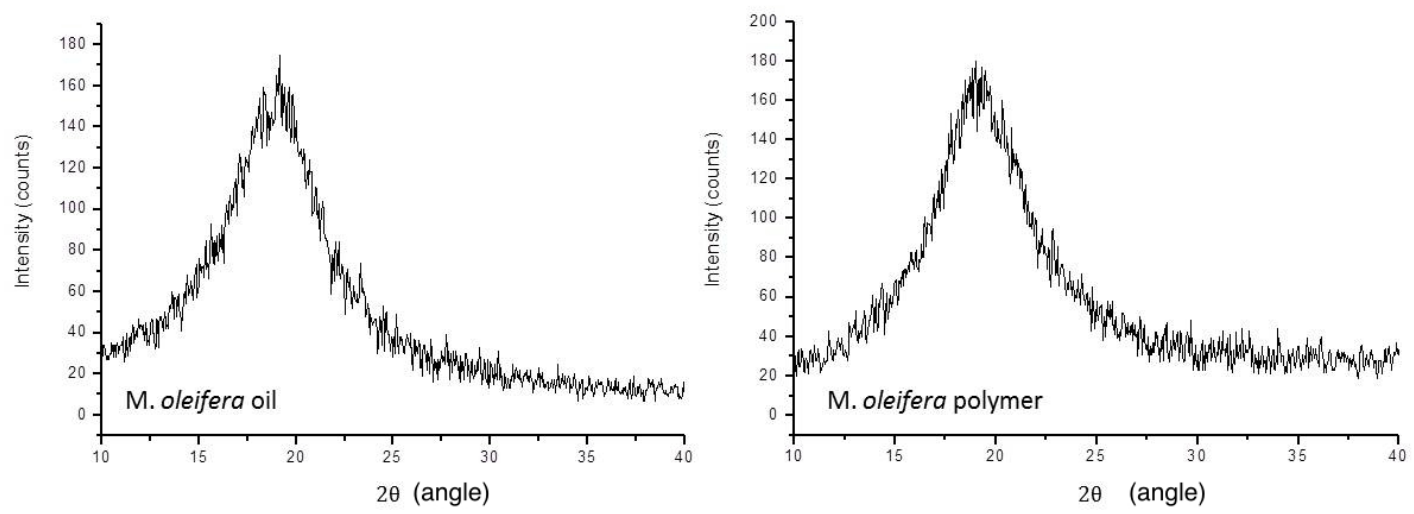

Figure 6. Diffractograms of M. oleifera oil and M. oleifera polymer. 

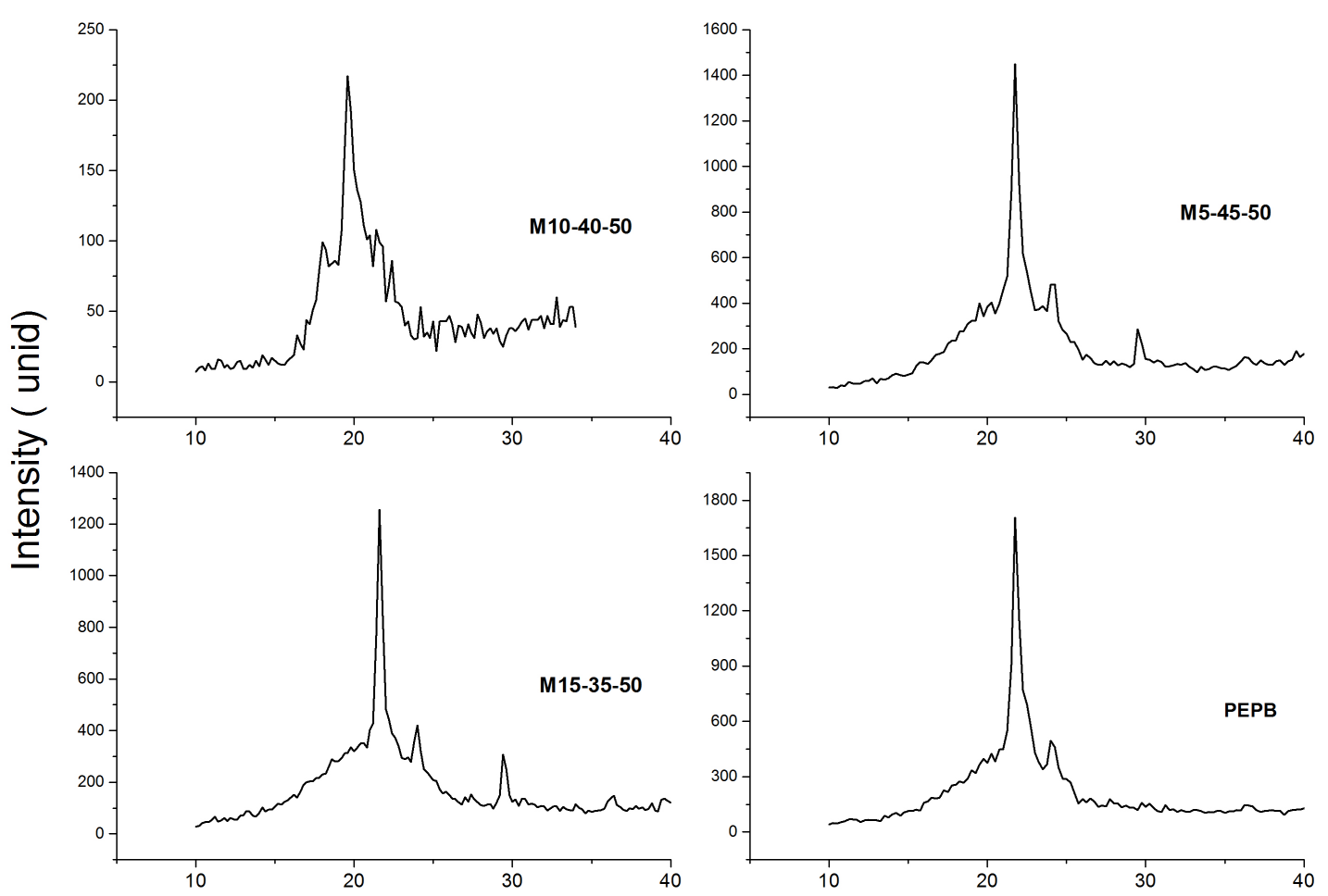

\section{$2 \theta$}

Figure 7. Diffractograms of samples with moringa oil.
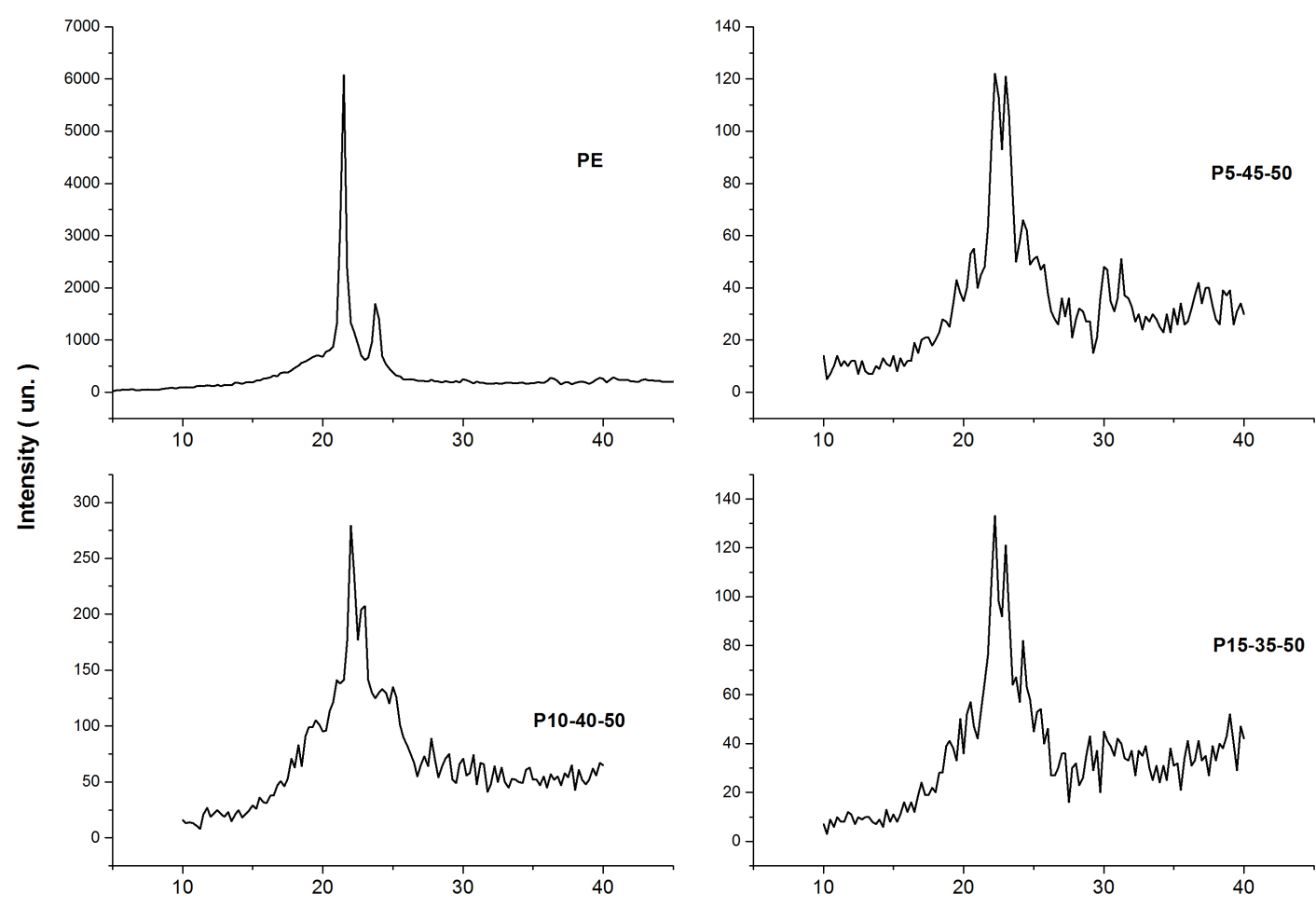

$2 \theta$

Figure 8. Diffractograms of moringa polymer. 
$50 \%$ for $\mathrm{PE}$. The mixture PEPB presents worse mechanical properties than LDPE and PBAT/PLA.

The addition of moringa components in mixture of PEPB increase the rupture force from $0.85 \mathrm{Kgf}$ to $1.05 \mathrm{Kgf}$ of $\mathrm{MO}$ and to $1.30 \mathrm{Kgf}$ of PMO. MO addition improves the ductility of PEPB and reduces elastic modulus. PMO improved the processability when reducing the stiffness of PEPB (elastic modulus) which had improved the ductility. PMO turned tensile stretch of P15-35-50 similar to PE and increased the percent elongation. PMO addition improved the mechanical properties loss with the mixture of polymers more than MO.

\subsection{Biodegradation tests}

MO15-35-50 and P15-35-50 were selected for analysis due to present the higher concentration of moringa components without problems like exudation and better results in thermal analysis. Previous studies about PB's degradation in Bartha Respirometer (Figure 1) showed a mass loss of approximately $30 \%$, but with a lower carbon production[40]. The biodegradation of the samples in Bartha Respirometer showed that the process of assimilation of carbon exhibit a higher effectiveness comparing to the one with no presence of moringa oil. The samples lost $8 \%$ of mass but the biodegradation indicates the production of $3.541 \mathrm{mg}$ of carbon biodegraded.

The mixture PEPB with MO improves the thermal resistance and the biodegradation behavior. The micrographs before biodegradation (Figure 9) showed a homogeneous form and after biodegradation showed a spongy form (Figure 10) due to the microorganism attack.

The biodegradability analysis with Bartha Respirometer verified the biodegradation capacity of samples using a

Table 1. Results of Tensile stretch test.

\begin{tabular}{cccrrr}
\hline & PE* & PB & \multicolumn{1}{c}{ PEPB } & \multicolumn{1}{c}{ M15 } & \multicolumn{1}{c}{ P15 } \\
\hline Tensile stress (MPa) & $10 \pm 0.8$ & $44.3 \pm 8.5$ & $8.9 \pm 2.3$ & $9.1 \pm 2.1$ & $9.7 \pm 1.8$ \\
Elastic modulus (Mpa) & $220 \pm 10.5$ & $630 \pm 23.5$ & $103.1 \pm 5.4$ & $33.1 \pm 5.2$ & $51.3 \pm 4.2$ \\
Elongation (\%) & $450 \pm 22.1$ & $285 \pm 8.7$ & $15 \pm 2.7$ & $22 \pm 3.4$ & $19 \pm 2.7$ \\
\hline
\end{tabular}

*BASF Report for films at $50 \mu \mathrm{m}$. PE (polyethylene); PB (biodegradable polymer); PEPB (mixture 1:1 of PE and PB); M15 (sample M15-35-50); P15 (sample P15-35-50).

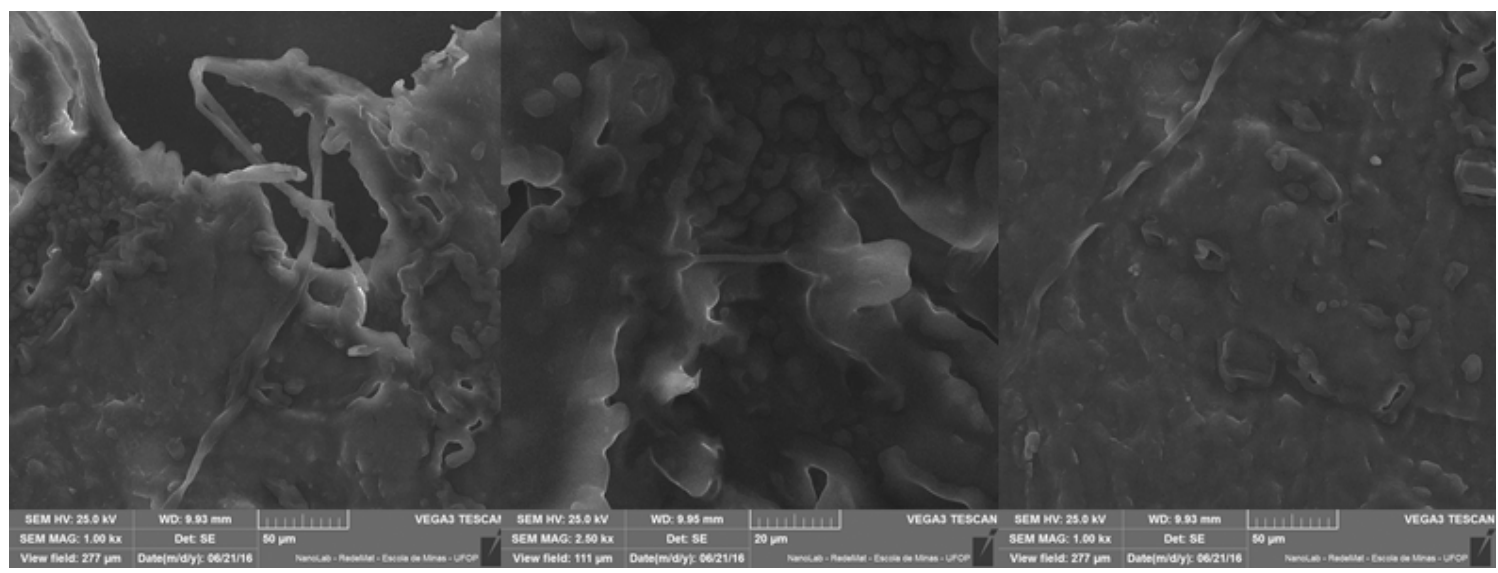

Figure 9. Micrography of M15-35-50 before biodegradation using Bartha Respirometer.

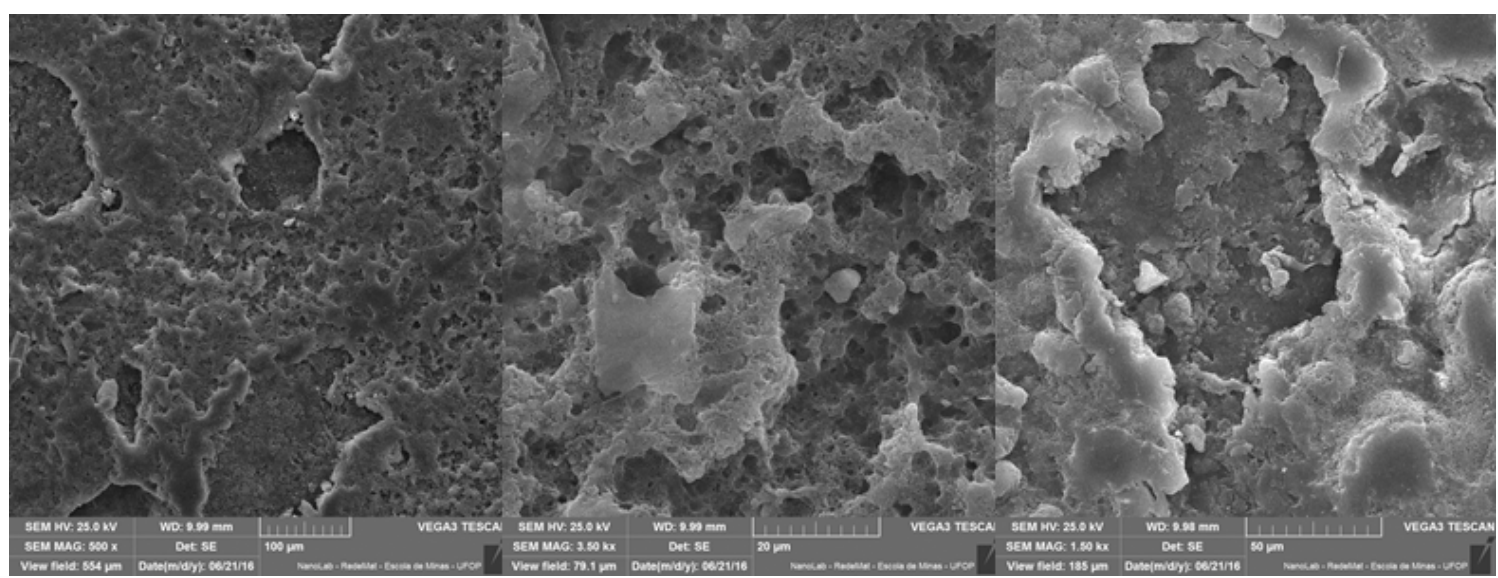

Figure 10. Micrography of M15-35-50 after biodegradation using Bartha Respirometer. 

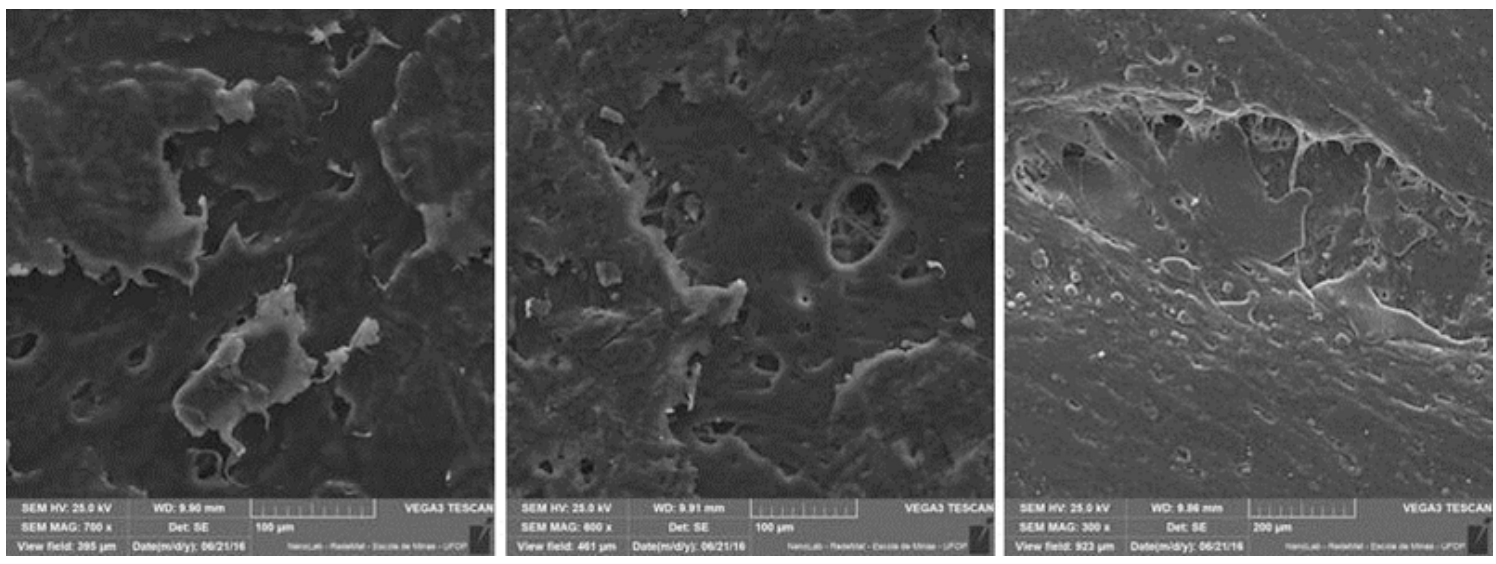

Figure 11. Micrography of P15-35-50 before biodegradation using Bartha Respirometer.

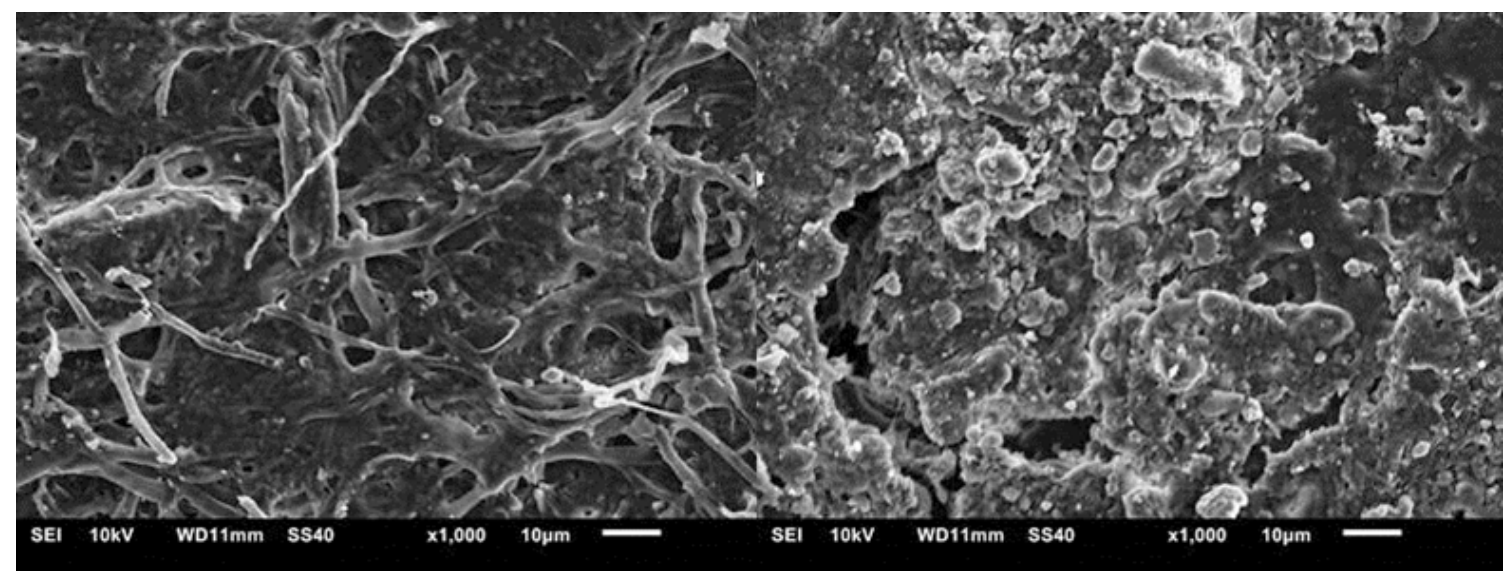

Figure 12. Micrography of P15-35-50 after biodegradation using Bartha Respirometer.

controlled atmosphere to quantify the $\mathrm{CO}_{2}$ produced during the process. The results of tests with $\mathrm{PEPB}$, and its mixtures, with $\mathrm{MO}$ and $\mathrm{PMO}$ verified that films with $\mathrm{MO}$ and $\mathrm{PMO}$ exhibit enhance of the biodegradation capacity of mixture with PEPB. In analysis with P15-35-50, after 9 weeks, the mixture $\mathrm{PEPB}$ produced $15 \mathrm{mg}$ of $\mathrm{CO}_{2}$, the sample produced $71 \mathrm{mg}$ of $\mathrm{CO}_{2}$ and the sample M15-35-50 produced $23 \mathrm{mg}$ of $\mathrm{CO}_{2}$. After 17 weeks, $\mathrm{P} 15-35-50$ produced $113 \mathrm{mg}$ of $\mathrm{CO}_{2}$, M15-35-50 produced $44 \mathrm{mg}$ and PEPB produced $33 \mathrm{mg}$ of $\mathrm{CO}_{2}$. The free test of biodegradation showed that P15-35-50 lost $51 \%$ of its weight while M15-35-50 lost $38 \%$ of it.

P15-35-50 before the biodegradation process (Figure 11) showed an uniform surface. After Bartha Respirometer tests, the sample showed structures similar to fibers (Figure 12) which indicated the compatibilizer behavior of PMO in PEPB mixture.

\section{Conclusions}

The best film resultant from the mixtures of $\mathrm{MO} / \mathrm{PMO}$, LDPE and PB exhibits proportions of $15 \%$ in mass of moringa components, $35 \%$ in mass of $\mathrm{PE}$ and $50 \%$ in mass of PB. The polymer produced from the oil of Moringa oleifera increased its thermal stability for the samples with 15\%. The P15-35-50 sample has the best composition and a higher thermal stability. The sample P15-5-50 showed the increase of $80 \%$ of biodegradation capacity comparing to the mixture PEPB and $35 \%$ in comparison to a similar mixture of MO with PEPB. Both M15-35-50 and P15-35-50 weren't fragmented even losing mass after the biodegradation tests, which indicates that fragmentation stage didn't occur. In sample M15-35-50, the spongy form after biodegradation test indicates the plasticizer behavior of moringa oil. The presence of fibers in biodegradation test of P15-35-50 indicated a compatibilizer behavior of moringa polymer. The addition of moringa oil improved the biodegradation capacity up to $31 \%$ and the thermal resistance up to $10 \%$. Also, it increased the ductility of the mixture of LDPE with PLA/PBAT, but some loss in the tensile stretch. On the other hand, the moringa polymer addition improved the biodegradation capacity up to $81 \%$, the same thermal resistance of oil addition, while increasing the ductility and the tensile stretch, to higher values than PEPB and MO films.

\section{References}

1. Aguilera, A. F., Tolvanen, P., Eränen, K., Leveneur, S., \& Salmi, T. (2016). Epoxidation of oleic acid under conventional heating and microwave radiation. Chemical Engineering and 
Processing: Process Intensification, 102, 70-87. http://dx.doi. org/10.1016/j.cep.2016.01.011.

2. Ahid Nunes, T. C., Barros, H. D., Barbosa, C. R. M., Barbosa, F. M., Filgueira, P. P. A., \& Pannirselvam, P. V. (2010). Tecnologia de Moringa oleifera como alimento funcional para a saude humana e animal. In Anais do II Encontro Nacional de Moringa (p. 7). Aracaju: Rede Sergipe Rede Petróleo e Gás de Sergipe, Rede Sergipe Biodiesel.

3. Al-Itry, R., Lamnawar, K., \& Maazouz,A. (2014). Rheological, morphological, and interfacial properties of compatibilized PLA/PBAT blends. Rheologica Acta, 53(7), 501-517. http:// dx.doi.org/10.1007/s00397-014-0774-2.

4. Poiana, M.-A., Mousdis, G., Alexa, E., Moigradean, D., Negrea, M., \& Mateescu, C. (2012). Application of FTIR spectroscopy in the assessment of olive oil adulteration. Journal of Agroalimentary Processes and Technologies, 18(4), 277-282. Retrieved in 2017, May 31, from https://www. journal-of-agroalimentary.ro/Journal-of-AgroalimentaryProcesses-and-Technologies-Article_Db742.html

5. Andrade, G. F., Melo, T. M. S., Guedes, C. D., Novack, K. M., dos Santos, R. C., \& Silva, M. E. (2011). Biological evaluation of crude and degummed oil from Moringa oleifera seeds. Brazilian Archives of Biology and Technology, 54(5), 10031006. http://dx.doi.org/10.1590/S1516-89132011000500018.

6. Bhutada, P. R., Jadhav, A. J., Pinjari, D. V., Nemade, P. R., \& Jain, R. D. (2016). Solvent assisted extraction of oil from Moringa oleifera Lam. seeds. Industrial Crops and Products, 82, 74-80. http://dx.doi.org/10.1016/j.indcrop.2015.12.004.

7. Bicalho, L. A., Novack, K. M., \& Melo, T. M. S. (2011). Avaliação da biodegradação de filmes de polietileno reciclado dopados com óleo de Moringa oleigera. In Anais do 11 Congresso Brasileiro de Polimeros (p. 1782-1790). Campos do Jordão: ABPol.

8. Castro-Aguirre, E., Auras, R., Selke, S., Rubino, M., \& Marsh, T. (2017). Insights on the aerobic biodegradation of polymers by analysis of evolved carbon dioxide in simulated composting conditions. Polymer Degradation \& Stability, 137, 251-271. http://dx.doi.org/10.1016/j.polymdegradstab.2017.01.017.

9. Da Porto, C., Decorti, D., \& Natolino, A. (2016). Microwave pretreatment of Moringa oleifera seed: effect on oil obtained by pilot-scale supercritical carbon dioxide extraction and Soxhlet apparatus. The Journal of Supercritical Fluids, 107, 38-43. http://dx.doi.org/10.1016/j.supflu.2015.08.006.

10. Dou, H., \& Kister, J. (2016). Research and development on Moringa oleifera: comparison between academic research and patents. World Patent Information, 47, 21-33. http://dx.doi. org/10.1016/j.wpi.2016.09.001.

11. Dubey, K. A., Chaudhari, C. V., Raje, N., Panickar, L., Bhardwaj, Y. K., \& Sabharwal, S. (2012). Radiation-assisted morphology modification of LDPE/TPS Blends: a study on starch degradation-processing- morphology correlation. Polymers \& Polymer Composites, 124, 3501-3510. http:// dx.doi.org/10.1002/app.

12. Fakayode, O. A., \& Ajav, E. A. (2016). Process optimization of mechanical oil expression from Moringa (Moringa oleifera) seeds. Industrial Crops and Products, 90, 142-151. http:// dx.doi.org/10.1016/j.indcrop.2016.06.017.

13. Finzi-Quintao, C. M., Novack, K. M., \& Bernardes-Silva, A. C. (2016). Identification of biodegradable and oxo-biodegradable plastic bags samples composition. Macromolecular Symposia, 367(1), 9-17. http://dx.doi.org/10.1002/masy.201500156.

14. Gaines, T. W., Williams, K. R., Wagener, K. B., \& Rojas, G. (2015). Microwave-assisted ADMET polymerization. Tetrahedron Letters, 56(25), 3923-3927. http://dx.doi. org/10.1016/j.tetlet.2015.04.122.
15. Gillie, J. K., Hochlowski, J., \& Arbuckle-Keil, G. (2000). Infrared spectroscopy. Analytical Chemistry, 72(12), 71R-79R. http://dx.doi.org/10.1021/a1000006w. PMid:10882198.

16. Gopalakrishnan, L., Doriya, K., \& Kumar, D. S. (2016). Moringa oleifera: a review on nutritive importance and its medicinal application. Food Science and Human Wellness, 5(2), 1-8. http://dx.doi.org/10.1016/j.fshw.2016.04.001.

17. Harding, K. G., Dennis, J. S., von Blottnitz, H., \& Harrison, S. T. L. (2007). Environmental analysis of plastic production processes: comparing petroleum-based polypropylene and polyethylene with biologically-based poly-hydroxybutyric acid using life cycle analysis. Journal of Biotechnology, 130(1), 57-66. http://dx.doi.org/10.1016/j.jbiotec.2007.02.012. PMid: 17400318.

18. Imre, B., \& Pukánszky, B. (2013). Compatibilization in biobased and biodegradable polymer blends. European Polymer Journal, 49(6), 1215-1233. http://dx.doi.org/10.1016/j. eurpolymj.2013.01.019.

19. Jia, P. Y., Bo, C. Y., Zhang, L. Q., Hu, L. H., Zhang, M., \& Zhou, Y. H. (2015). Synthesis of castor oil based plasticizers containing flame retarded group and their application in poly (vinyl chloride) as secondary plasticizer. Journal of Industrial and Engineering Chemistry, 28, 217-224. http:// dx.doi.org/10.1016/j.jiec.2015.02.017.

20. Jovanovic, J., \& Adnadjevic, B. (2007). Comparison of the kinetics of conventional and microwave methyl methacrylate polymerization jelena. Journal of Applied Polymer Science, 104(3), 1775-1782. http://dx.doi.org/10.1002/app.25827.

21. Kampars, V., Kronberga, S., Vlachos, N., Skopelitis, Y., Psaroudaki, M., Konstantinidou, V., \& Tegou, E. (2006). Applications of Fourier transform-infrared spectroscopy to edible oils. Analytica Chimica Acta, 573-574, 459-465. http:// dx.doi.org/10.1016/j.aca.2006.05.034. PMid:17723561.

22. Leveneur, S., Ledoux, A., Estel, L., Taouk, B., \& Salmi, T. (2014). Epoxidation of vegetable oils under microwave irradiation. Chemical Engineering Research \& Design, 92(8), 1495-1502. http://dx.doi.org/10.1016/j.cherd.2014.04.010.

23. Mekewi, M. A., Ramadan, A. M., ElDarse, F. M., Abdel Rehim, M. H., Mosa, N. A., \& Ibrahim, M. A. (2017). Preparation and characterization of polyurethane plasticizer for flexible packaging applications: natural oils affirmed access. Egyptian Journal of Petroleum, 6(1), 9-15. http://dx.doi.org/10.1016/j. ejpe.2016.02.002.

24. Melo, T. M. S., Novack, K. M., \& Leandro, C. (2011). Termopolimerização do óleo de Moringa oleifera. In Anais do 11 Congresso Brasileiro de Polimeros. Campos do Jordão: ABPol.

25. Miao, S., Wang, P., Su, Z., \& Zhang, S. (2014). Vegetableoil-based polymers as future polymeric biomaterials. Acta Biomaterialia, 10(4), 1692-1704. http://dx.doi.org/10.1016/j. actbio.2013.08.040. PMid:24012607.

26. Nguyen, N. T., Greenhalgh, E., Kamaruddin, M. J., El harfi, J., Carmichael, K., Dimitrakis, G., Kingman, S. W., Robinson, J. P., \& Irvine, D. J. (2014). Understanding the acceleration in the ring-opening of lactones delivered by microwave heating. Tetrahedron, 70(4), 996-1003. http://dx.doi.org/10.1016/j. tet.2013.11.031

27. Karak, N. (2012). Vegetable oil-based polymers: properties, processing and applications. Philadelphia: Woodhead Publising.

28. Rashed, M. M., Kalam, M. A., Masjuki, H. H., Mofijur, M., Rasul, M. G., \& Zulkifli, N. W. M. (2016). Performance and emission characteristics of a diesel engine fueled with palm, jatropha, and moringa oil methyl ester. Industrial Crops and Products, 79, 70-76. http://dx.doi.org/10.1016/j.indcrop.2015.10.046.

29. Rouane, A., Zerrouki, D., \& Benaniba, M. T. (2014). Effect of sunflower oil on the mechanical permanence and the thermal 
properties of poly (vinyl chloride). Energy Procedia, 50, 285289. http://dx.doi.org/10.1016/j.egypro.2014.06.035.

30. Sander, M. M., Nicolau, A., Guzatto, R., \& Samios, D. (2012). Plasticiser effect of oleic acid polyester on polyethylene and polypropylene. Polymer Testing, 31(8), 1077-1082. http:// dx.doi.org/10.1016/j.polymertesting.2012.08.006.

31. Schlemmer, D., Sales, M. J. A., \& Resck, I. S. (2010). Preparação, caracterização e degradação de blendas PS/TPS usando glicerol e óleo de buriti como plastificantes. Polímeros: Ciência e Tecnologia, 20(1), 6-13. http://dx.doi.org/10.1590/ S0104-14282010005000002.

32. Schlemmer, D., Sales, M. J. A., \& Resck, I. S. (2009). Degradation of different polystyrene/thermoplastic starch blends buried in soil. Carbohydrate Polymers, 75(1), 58-62. http://dx.doi.org/10.1016/j.carbpol.2008.06.010.

33. Sikorska, W., Musiol, M., Nowak, B., Pajak, J., Labuzek, S., Kowalczuk, M., \& Adamus, G. (2015). Degradability of polylactide and its blend with poly[(R,S)-3-hydroxybutyrate] in industrial composting and compost extract. International Biodeterioration \& Biodegradation, 101, 32-41. http://dx.doi. org/10.1016/j.ibiod.2015.03.021.

34. Kale, S. K., Deshmukh, A. G., Dudhare, M. S., \& Patil, V. B. (2015). Microbial degradation of plastics: a review. Journal of Biochemical Technology, 6(1), 952-961. http://dx.doi. org/10.1504/IJEP.2008.016895.

35. Tabasi, R. Y., \& Ajji, A. (2015). Selective degradation of biodegradable blends in simulated laboratory composting.
Polymer Degradation \& Stability, 120, 435-442. http://dx.doi. org/10.1016/j.polymdegradstab.2015.07.020.

36. Vieira, M. G. A., Da Silva, M. A., Santos, L. O., \& Beppu, M. M. (2011). Natural-based plasticizers and biopolymer films: a review. European Polymer Journal, 47(3), 254-263. http:// dx.doi.org/10.1016/j.eurpolymj.2010.12.011.

37. Vlachos, N., Skopelitis, Y., Psaroudaki, M., Konstantinidou, V., Chatzilazarou, A., \& Tegou, E. (2006). Applications of Fourier transform-infrared spectroscopy to edible oils. Analytica Chimica Acta, 573-574, 459-465. http://dx.doi.org/10.1016/j. aca.2006.05.034. PMid:17723561.

38. Xia, L., Cao, D., Zhang, H., \& Guo, Y. (2016). Study on the classical and rheological properties of castor oil-polyurethane pre polymer (C-PU) modified asphalt. Construction \& Building Materials, 112, 949-955. http://dx.doi.org/10.1016/j. conbuildmat.2016.02.207.

39. Yeh, J.-T., Tsou, C.-H., Huang, C.-Y., Chen, K.-N., Wu, C.-S., Chai, W.-L., \& Lv, J. (2010). Compatible and crystallization properties of poly(lactic acid)/poly(butylene adipate-coterephthalate) blends. Journal of Applied Polymer Science, 116(2), 680-687. http://dx.doi.org/10.1002/app.

Received: May 31, 2017 Revised: Oct. 24, 2017 Accepted: Oct. 29, 2017 